\title{
Do personal beliefs and peers affect the practice of alcohol consumption in university students in Lebanon?
}

\author{
J. Salamé, ${ }^{7}$ B. Barbour ${ }^{2}$ and P. Salameh ${ }^{3,4}$
}

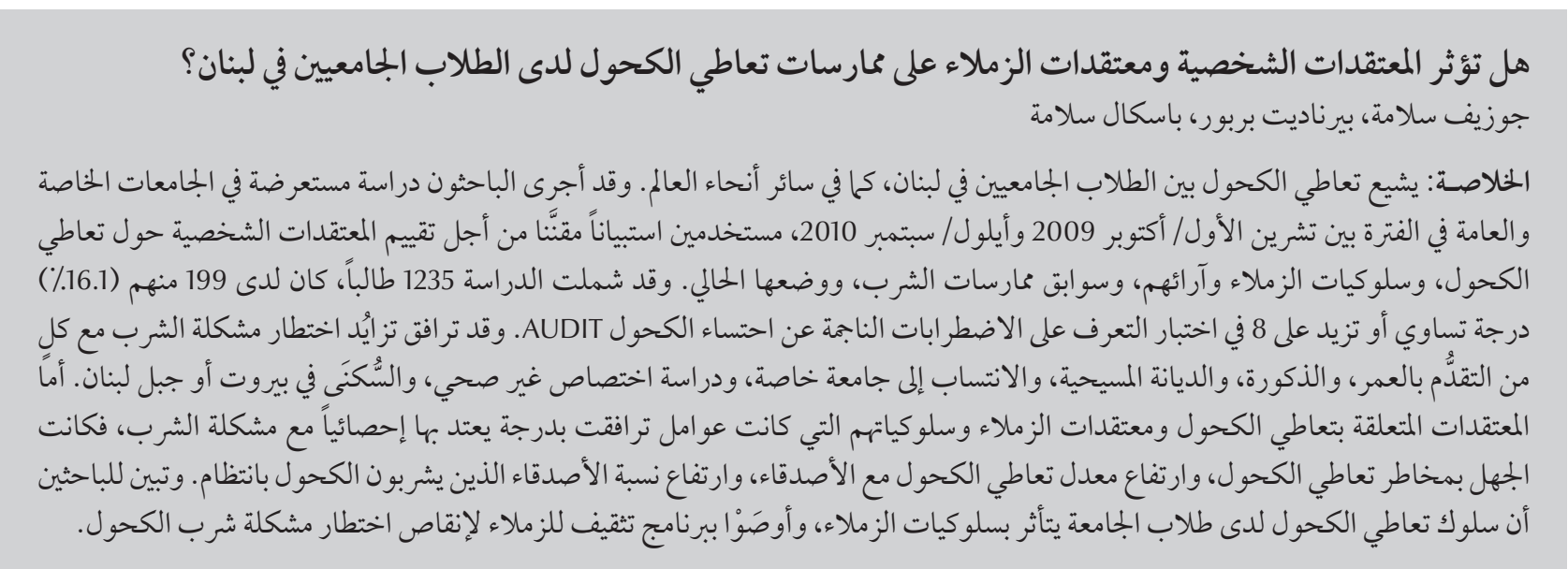

ABSTRACT Alcohol consumption is frequent among university students in Lebanon as elsewhere in the world. A crosssectional study was conducted in Lebanon's public and private universities between October 2009 and September 2010 using a standardized questionnaire to assess personal beliefs about alcohol consumption, peers' behaviours and opinions and history of and current drinking practices. Of 1235 students, 199 (16.1\%) had an AUDIT score $\geq 8$. Older age, male sex, Christian religion, attending a private university, studying a non-health specialty and residing in Beirut or Mount Lebanon were associated with a higher risk of harmful drinking. Beliefs concerning alcohol consumption and peers' opinions and behaviours were factors significantly associated with harmful drinking, especially: ignoring the dangers of alcohol consumption; higher frequency of consumption with friends; and a higher proportion of friends who drank regularly. University students' alcohol drinking behaviour was mostly influenced by peers' behaviour, and a peer education programme is recommended to decrease the risk of harmful drinking.

Les croyances personnelles et celles des pairs influent-elles sur la consommation d'alcool des étudiants au Liban?

RÉSUMÉLaconsommation d'alcoolestfréquentechezlesétudiantsauLiban commeailleurs. Uneétudetransversale a été menée dans des universités publiques et privées du Liban, entre octobre 2009 et septembre 2010, à l'aide d'un questionnaire normalisé visant à évaluer les croyances personnelles en matière de consommation d'alcool, le comportement des pairs et leurs opinions ainsi que les pratiques passées et présentes de consommation d'alcool. Sur un total de 1235 étudiants, 199 (16,1\%) ont obtenu un score AUDIT supérieur ou égal à 8. Être plus âgé, de sexe masculin, ou chrétien, fréquenter une université privée, étudier un autre domaine que la santé, vivre à Beyrouth ou dans la région du Mont-Liban étaient des facteurs associés à un risque accru de consommation nocive d'alcool. Les croyances concernant la consommation d'alcool et l'opinion et le comportement des pairs étaient des facteurs significativement associés à une consommation nocive d'alcool, en particulier le fait d'ignorer les dangers de la consommation d'alcool, d'en consommer fréquemment avec des amis et d'avoir une proportion élevée d'amis qui en consomment régulièrement. Le comportement des étudiants concernant la consommation d'alcool était principalement influencé par celui des pairs. Un programme d'éducation par les pairs est recommandé pour diminuer le risque de consommation nocive d'alcool.

${ }^{7}$ Faculty of Medicine; ${ }^{2}$ Faculty of Public Health; ${ }^{3}$ Faculty of Pharmacy; ${ }^{4}$ Faculty of Public Health, Lebanese University, Beirut, Lebanon (Correspondence to P. Salameh:psalameh@ul.edu.l; pascalesalameh1@hotmail.com).

Received: 21/02/12; accepted: 19/03/12 


\section{Introduction}

Alcohol consumption is common among university students all over the world $[1,2]$ and is associated with social [3] and health problems [4] in this population subgroup. For example, alcohol consumption may lead to low academic achievement [5], psychological disturbances [6], social and relational problems [3], illicit drug abuse [7] and physical health problems [4].

In Eastern Mediterranean countries, very few data have been gathered concerning alcohol consumption in general, or by university students in particular [8]. In Lebanon, a study published in 2000 on a limited sample from 2 private universities showed that $49 \%$ of students had ever consumed alcohol, $2.4 \%$ were alcohol dependent and $2.1 \%$ were alcohol abusers [9]. However, underreporting of this habit is likely for religious and social reasons (since alcohol drinking is prohibited in Islam). Therefore, while talking about alcohol consumption is a taboo in our conservative society [10], we suspect that harmful alcohol drinking is increasingly common in this young population.

The objectives of this study were to confirm the validity of the AUDIT score in the Lebanese context before using it to assess harmful drinking in Lebanese students, and to evaluate whether personal beliefs about alcohol consumption and peers' drinking affected alcohol consumption practice and harmful drinking of university students.

\section{Methods}

\section{Study design}

We conducted a cross-sectional study in Lebanon's public and private universities, between October 2009 and September 2010.

\section{Population and sampling procedure}

A cluster proportionate sampling method was used to select students within campuses. From the list of universities provided by the Ministry of Higher Education, we selected universities with the highest proportion of students in Lebanon (1\% of students and more). In the public university (Lebanese University; $43.3 \%$ of total university students in Lebanon), we sampled all faculties: the faculties of Arts, Law and Political Sciences, Public Health, Medical Sciences, Engineering, Economics, Information and Documentation, Social Sciences, Literature and Humanities and Sciences. The private universities selected were Kaslik Holy Spirit University (4.1\%), Saint Joseph University (5.6\%), Notre Dame University (2.9\%), Beirut Arab University (10.6\%), Balamand University (1.9\%), Sagesse University (1.0\%), American University of Lebanon (1.0\%), Lebanese American University (2.9\%), American University of Science and Technology (3\%), Lebanese Germany University (1\%) and Lebanese International University (4.6\%). The American University of Beirut (4.2\%) refused to participate to the study. In participating universities, we approached all students regardless of their field of specialization.

\section{Data collection}

Campus administrators were contacted and permission was given for enquirers to distribute a proportionate cluster sampling of questionnaires according to the number of students in every university. However, within every campus, an accidental sample of students was selected, because administrators did not allow us to have lists of students and interview students accordingly.

A self-administered, anonymous questionnaire in Arabic language was prepared by the investigators and distributed to university students during breaks. Students gave their oral consent to participate to the study, after it had been explained to them that it was a "study done by university researchers that had extreme importance for their health" and ensuring anonymity (no names were required). To ensure maximum objectivity in students' answers, enquirers were instructed not to give any additional clarification for questions that were not understood. The questionnaire was pilot-tested on 30 university students to correct or clarify questions when necessary.

\section{Sample size calculation}

Sample size calculation was performed using the following assumptions: a prevalence of harmful alcohol consumption of $9 \%$ [11], and worst acceptable values of $(6.5 \%-11.5 \%)$ (a bracket of $5 \%$ around $9 \%)$. The minimal acceptable sample size was calculated to be 503 individuals; taking into account cluster sampling, the number was doubled to 1006. Afterwards, we added an additional number of questionnaires (33\%) to allow for non-response. Thus, a total of 1500 questionnaires were distributed to students from all universities.

\section{Study tool}

A standardized questionnaire, including closed and open-ended questions, was used. Questions about personal beliefs concerning alcohol consumption and peers' behaviours and opinions were asked. For example, we asked whether students believed that alcohol drinking was dangerous for health, if alcohol was dangerous when consumed frequently and massively, if alcohol was dangerous for pregnant women and if driving after a drink was dangerous. We also asked about the attitudes of their friends towards alcohol consumption and personal attitudes towards drinking, heavy drinking and causes of alcohol consumption or non-consumption. To study practices, we evaluated details of alcohol consumption, age of first and 
of regular consumption, place of first alcohol consumption, frequency of high consumption, maximal number of drinks on one occasion, proportion of friends who frequently drink alcohol and frequency of alcohol consumption with friends.

To assess harmful alcohol consumption, we used the AUDIT score recommended by the World Health Organization $[12,13]$. The score questions were translated into Arabic by an independent translator and back-translated into English by the researchers to resolve any translation discrepancy. A cut-off value of 8 was considered predictive of harmful drinking [12-14].

\section{Statistical analysis}

Data was entered, managed and analysed by SPSS, version 13.0. Before proceeding with the analysis, we first validated the AUDIT score in the context where it was used: we first performed an exploratory factor analysis using the principal component analysis technique, and extracted the factors with an eigenvalue that was higher than 1 , after ensuring sampling adequacy by Kaiser-Meyer-Olkin measure and Bartlett test of sphericity. Since the extracted factors were correlated, we used the Promax rotation to show the most appropriate pattern and structure matrix. We also calculated the Cronbach alpha factor for reliability analysis.

We also weighted the result to adjust for the distribution of students between public and private universities according to the list provided by the Ministry of Education. Harmful alcohol drinking according to the AUDIT score was considered as a dependent variable. The independent variables were as follows: age, type of university, religion, sex, age of initiation of alcohol consumption, age of first alcohol consumption and region of residence. In addition, personal and peers' beliefs and attitudes about alcohol were used as independent variables.

Missing values, which accounted for $<5 \%$ of answers, were not replaced, and variables were analysed as available. The chi-squared test was used for comparison between categorical variables. The Student $t$-test was used to compare means of continuous variables. Variables showing association in the bivariate analysis at the $P<0.2$ level were entered in the multivariate logistic regression models. In the logistic regression a nonsignificant Hosmer and Lemeshow test should be obtained $(P$-value $>0.05)$ to have an adequacy model.

\section{Results}

Out of 1500 distributed questionnaires, 1263 individuals (84.2\%) returned their questionnaires. After weighting individuals according to the distribution of public and private universities, the number became 1266 individuals (due to numbers rounding). Out of these, 1235 (97.6\%) had no missing values and were thus used for the majority of analyses.

\section{AUDIT score validity}

Table 1 shows the structure of the AUDIT score when applied to the university students in Lebanon with no missing values, after ensuring sampling adequacy with Kaiser-Meyer-Olkin measure of 0.872, and a Bartlett test of sphericity with a chi-square of 4052 and a $P$-value $<0.001$. When using a principal component analysis and a promax rotation, the AUDIT score items loaded on 2 factors (with eigenvalues > 1) that explained $53.7 \%$ of the total variance: the factor represented problems with drinking last year, while the second

\begin{tabular}{|c|c|c|c|}
\hline Items & $\begin{array}{l}\text { Factor } 1 \\
\text { loading }\end{array}$ & $\begin{array}{l}\text { Factor } 2 \\
\text { loading }\end{array}$ & Communality \\
\hline Frequency of feeling a morning urge to drink in previous 12 months & 0.753 & - & 0.433 \\
\hline Unable to stop drinking in previous 12 months & 0.681 & - & 0.554 \\
\hline Unable to remember what happened after drinking in previous 12 months & 0.677 & - & 0.591 \\
\hline Frequency of guilt after drinking in previous 12 months & 0.641 & - & 0.443 \\
\hline $\begin{array}{l}\text { Any person who was hurt in consequence of your alcohol consumption in previous } \\
12 \text { months }\end{array}$ & 0.633 & - & 0.316 \\
\hline $\begin{array}{l}\text { Unable to perform usual activities because of alcohol consumption in previous } 12 \\
\text { months }\end{array}$ & 0.549 & - & 0.481 \\
\hline Did anybody suggest to you that you should decrease your alcohol consumption? & 0.451 & - & 0.371 \\
\hline Frequency of consumption of 6 drinks and more on one occasion & - & 0.913 & 0.790 \\
\hline Mean number of drinks on one occasion & - & 0.903 & 0.759 \\
\hline Usual frequency of alcohol consumption & - & 0.813 & 0.631 \\
\hline Total AUDIT score correlation & $0.842^{*}$ & $0.862^{*}$ & $0.552^{* *}$ \\
\hline
\end{tabular}

${ }^{*} P<0.001$ for Pearson coefficients correlation with AUDIT score; ${ }^{*} P<0.001$ for Pearson coefficients correlation between factor 1 and factor 2. The reliability of the total AUDIT score and of both factors was 0.815 for the total, 0.734 for factor 1 and 0.803 for factor 2 . 
mostly represented the frequency and heaviness of alcohol consumption. The reliability of the total AUDIT score and of both factors was high: 0.815 for the total, 0.734 for factor 1 and 0.803 for factor 2 .

\section{Sample characteristics}

Out of 1235 individuals, 199 (16.1\%; 95\% CI: 14.0\%-18.2\%) had an AUDIT score of $\geq 8$ and were considered to have harmful drinking. In Table 2, we present the characteristics of the sample, divided into AUDIT scores $\leq 7(n=$ $1036 ; 83.9 \%)$ and $\geq 8(n=199 ; 16.1 \%)$. There were significant differences concerning alcohol consumption with respect to all the sociodemographic characteristics evaluated: higher age, male sex, Christian religion, attending a private university, studying a nonhealth specialty and dwelling in Beirut or the Mount Lebanon region were associated with a higher probability of harmful alcohol drinking $(P<0.05$ for all) (Table 2) .

\section{Personal beliefs and practice concerning alcohol consumption}

Believing that alcohol was not dangerous for health (crude $\mathrm{OR}=6.67$ ) and thinking that it was acceptable to get drunk sometimes $(O R=5.39)$, particularly if good grades were achieved at university $(O R=8.21)$, significantly increased the risk of harmful drinking $(P$ $<0.001$ ) (Table 3). Moreover, knowing that frequent and massive consumption of alcohol was dangerous ( $\mathrm{OR}=$ 1.42) and that alcohol was dangerous for pregnant women $(\mathrm{OR}=1.94)$ significantly affected the risk of harmful drinking. However, believing that it was dangerous to drink and drive did not have a significant association with harmful drinking (Table 3). The mean age at first consumption was lower in individuals with harmful drinking $[13.6$ (SD 3.2) versus 15.2 (SD 2.6) years] $(P<0.001)$ and their mean maximal number of drinks on one occasion was higher $[11.0(\mathrm{SD} 6.9)$ versus 5.3 (SD 6.8)] $(P<0.001)$.

\section{Peers behaviours and opinion and association with harmful drinking}

Table 4 shows that peers' opinion about drinking and behaviours strongly affected the students' risk of harmful drinking. Risk factors for harmful drinking were: friends' agreeing with alcohol consumption (crude $\mathrm{OR}=6.22$ ), higher proportion of friends who drank regularly (OR $=17.3)$ and higher frequency of drinking alcohol with friends $(\mathrm{OR}=80.1)$. Likewise, having had their first drink with friends $(O R=3.27)$, at a relative's house $(\mathrm{OR}=1.81)$ significantly increased the risk of harmful drinking versus first drinking alcohol in a public place.

\begin{tabular}{|c|c|c|c|c|c|c|}
\hline \multirow[t]{2}{*}{ Characteristic } & \multicolumn{2}{|c|}{$\begin{array}{c}\text { AUDIT score }<8 \\
(n=1036)\end{array}$} & \multicolumn{2}{|c|}{$\begin{array}{c}\text { AUDIT score } \geq 8 \\
(n=199)\end{array}$} & \multirow[t]{2}{*}{$P$-value } & \multirow[t]{2}{*}{ OR $(95 \% \mathrm{Cl})$} \\
\hline & No. & $\%$ & No. & $\%$ & & \\
\hline Age group (years) & & & & & 0.009 & \\
\hline $17-19$ & 351 & 88.0 & 48 & 12.0 & & Ref. \\
\hline $20-21$ & 500 & 83.2 & 101 & 16.8 & & $1.48(1.00-2.17)$ \\
\hline $22+$ & 184 & 79.0 & 49 & 21.0 & & $1.95(1.23-3.08)$ \\
\hline Sex & & & & & $<0.001$ & \\
\hline Male & 297 & 68.1 & 139 & 31.9 & & $5.75(4.13-8.00)$ \\
\hline Female & 737 & 92.5 & 60 & 7.5 & & Ref. \\
\hline Religion & & & & & $<0.001$ & \\
\hline Christian & 821 & 82.1 & 179 & 17.9 & & $2.41(1.47-3.95)$ \\
\hline Muslim & 210 & 91.7 & 19 & 8.3 & & Ref. \\
\hline \multicolumn{7}{|l|}{ Type of university } \\
\hline Public university & 484 & 90.1 & 53 & 9.9 & $<0.001$ & Ref. \\
\hline Private university & 552 & 79.1 & 146 & 20.9 & & $2.41(1.72-3.38)$ \\
\hline \multicolumn{7}{|l|}{ Specialty } \\
\hline Non-health specialty & 709 & 79.7 & 179 & 20.3 & 0.010 & $4.24(2.62-6.85)$ \\
\hline Health specialty & 333 & 94.3 & 20 & 5.7 & & Ref. \\
\hline Region of residence & & & & & 0.003 & \\
\hline Beirut & 136 & 79.5 & 35 & 20.5 & & $2.66(1.26-5.69)$ \\
\hline Mount Lebanon & 770 & 83.5 & 152 & 16.5 & & $2.04(1.07-3.98)$ \\
\hline Other region & 124 & 91.2 & 12 & 8.8 & & Ref. \\
\hline
\end{tabular}

Ref. = reference category; $O R=$ odds ratio; $C I=$ confidence interval . 


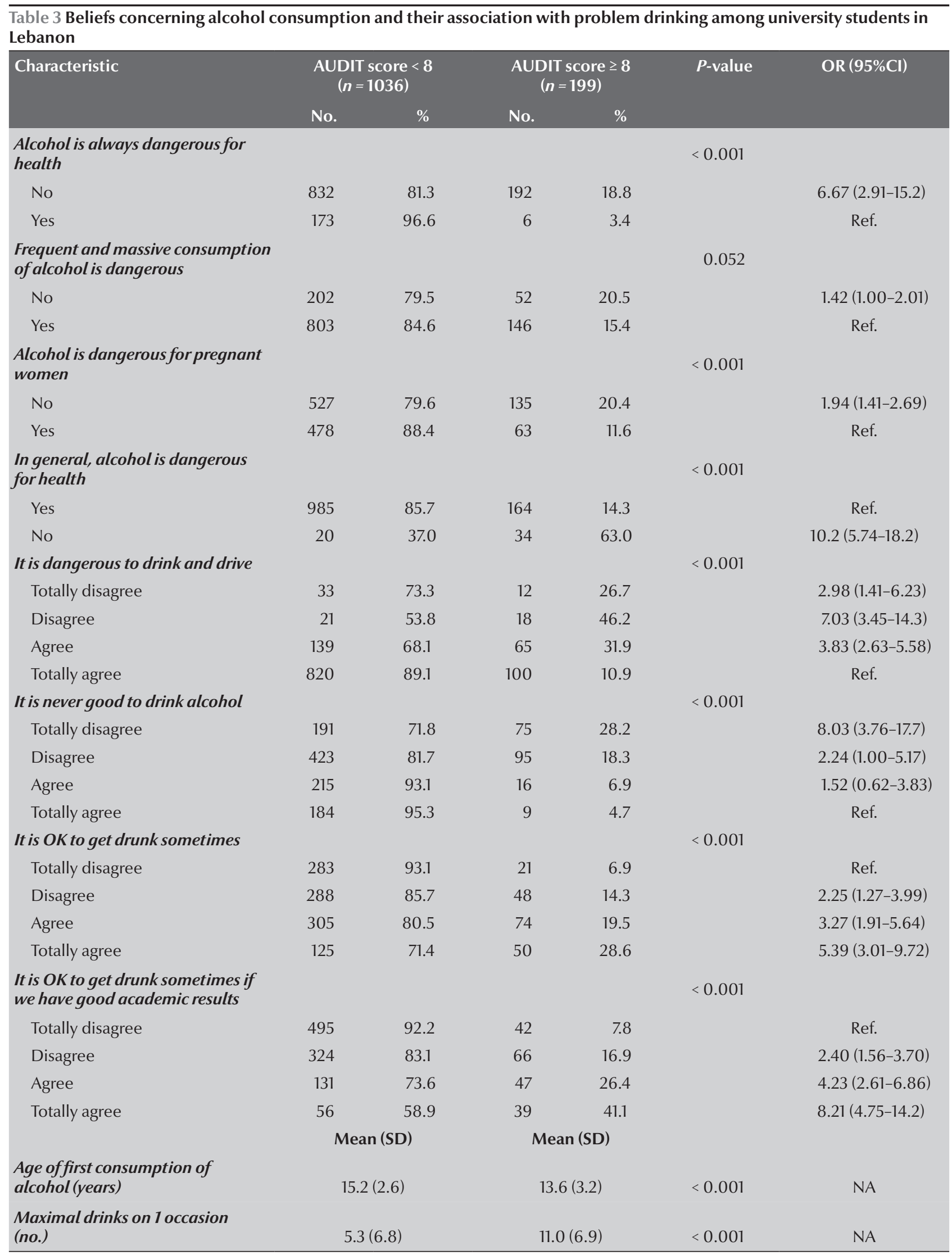

$S D=$ standard deviation; Ref. = reference category; $O R=$ odds ratio; $C l=$ confidence interval; $N A=$ not applicable. 


\begin{tabular}{|c|c|c|c|c|c|c|}
\hline \multirow[t]{2}{*}{ Characteristic } & \multicolumn{2}{|c|}{$\begin{array}{c}\text { AUDIT score }<8 \\
(n=1036)\end{array}$} & \multicolumn{2}{|c|}{$\begin{array}{c}\text { AUDIT score } \geq 8 \\
(n=199)\end{array}$} & \multirow[t]{2}{*}{$P$-value } & \multirow[t]{2}{*}{ OR $(95 \% \mathrm{CI})$} \\
\hline & No. & $\%$ & No. & $\%$ & & \\
\hline $\begin{array}{l}\text { Friends generally agree with } \\
\text { alcohol consumption }\end{array}$ & & & & & $<0.001$ & \\
\hline Yes, they do & 569 & 78.7 & 154 & 21.3 & & $6.22(2.60-15.9)$ \\
\hline They do not care & 277 & 87.9 & 38 & 12.1 & & $3.16(1.24-8.52)$ \\
\hline They disagree & 138 & 95.8 & 6 & 4.2 & & Ref. \\
\hline $\begin{array}{l}\text { Frequency of consumption } \\
\text { with friends }\end{array}$ & & & & & $<0.001$ & \\
\hline Almost every time & 68 & 41.5 & 96 & 58.5 & & $80.1(27.1-266)$ \\
\hline Almost half of the times & 112 & 70.4 & 47 & 29.6 & & $23.8(7.96-79.9)$ \\
\hline Less than half of the times & 91 & 91.0 & 9 & 9.0 & & $5.61(1.53-22.3)$ \\
\hline Occasionally & 476 & 91.7 & 43 & 8.3 & & $5.13(1.74-17.0)$ \\
\hline Never & 227 & 98.3 & 4 & 1.7 & & Ref. \\
\hline $\begin{array}{l}\text { Proportion of friends who drink } \\
\text { regularly }\end{array}$ & & & & & $<0.001$ & \\
\hline Almost all & 134 & 60.1 & 89 & 39.9 & & $17.3(7.79-39.8)$ \\
\hline More than half of them & 162 & 74.7 & 55 & 25.3 & & $8.83(3.92-20.7)$ \\
\hline Less than half of them & 155 & 89.6 & 18 & 10.4 & & $3.02(1.20-7.79)$ \\
\hline A few of them only & 317 & 93.0 & 24 & 7.0 & & $1.97(0.82-4.86)$ \\
\hline None of them & 208 & 96.3 & 8 & 3.7 & & Ref. \\
\hline $\begin{array}{l}\text { Place of first consumption of } \\
\text { alcohol }\end{array}$ & & & & & $<0.001$ & \\
\hline At home & 319 & 79.8 & 81 & 20.3 & & $1.36(0.92-2.02)$ \\
\hline At a relative's house & 71 & 74.7 & 24 & 25.3 & & $1.81(1.01-3.23)$ \\
\hline At a friend's house & 59 & 62.1 & 36 & 37.9 & & $3.27(1.92-5.59)$ \\
\hline At school & 4 & 80.0 & 1 & 20.0 & & $1.34(0.68-1.64)$ \\
\hline In a public place & 295 & 84.3 & 55 & 15.7 & & Ref. \\
\hline
\end{tabular}

Ref. = reference category; $O R=$ odds ratio; $C I=$ confidence interval .

\section{Multivariate analysis}

A stepwise descendent logistic regression was conducted (Table 5), and the following factors had an effect on harmful drinking: male sex (adjusted $\mathrm{OR}=2.36$ ), believing that frequent and massive consumption of alcohol was dangerous $(\mathrm{OR}=2.94)$, believing that youngsters agreed with drinking (OR $=1.43$; trend towards significance), higher frequency of consuming alcohol with friends $(O R=1.71)$ and a higher proportion of friends who drank alcohol regularly $(\mathrm{OR}=1.38)$. Other included variables in the model were removed by the procedure because of non-significant associations.

\section{Discussion}

We found that the AUDIT score had excellent construct validity and reliability in this sample of Lebanese students. Equivalent results were found by other researchers [15]. An important percentage of students (16.1\%) were found to have harmful alcohol consumption (AUDIT score $\geq 8$ ). This proportion is higher than that recently reported by Karam et al. in a rapid situation assessment for alcohol dependence in Lebanon (9\%) [11]. This may be due to the fact that harmful alcohol drinking includes the concepts of both alcohol dependence and binge drinking.
However, our results were similar to those found by the same authors in the 1990s on a sample taken from 2 private universities [16], where non-Christians and women were less likely to consume alcohol than Christians and men. Prohibition of alcohol consumption by Islam explains the higher number of students with harmful drinking in the Christian category than the Muslim one ( $\mathrm{OR}=$ 3.17).

Our results are comparable to those of a study of college students in the United States of America, many European countries and the Far East (Hong Kong), except for the sex ratio of consumers who had harmful drinking 


\begin{tabular}{lccc}
\hline Table 5 Multivariate analysis of factors associated with problem drinking among university students in Lebanon & \\
\hline Factor & ORa & $\mathbf{9 5 \%}$ Cl & $\boldsymbol{P}_{\text {-value }}^{\mathrm{a}}$ \\
Male sex & 2.36 & $1.52-3.66$ & $<0.001$ \\
Believing that frequent and massive consumption of alcohol is dangerous & 2.94 & $1.59-5.44$ & $<0.001$ \\
Believing that friends agree with drinking & 1.43 & $0.95-2.15$ & 0.083 \\
Higher frequency of alcohol consumption with friends & 1.71 & $1.43-2.06$ & $<0.001$ \\
Higher number of friends who drink regularly & 1.38 & $1.15-1.66$ & $<0.001$ \\
\hline
\end{tabular}

${ }^{a}$ Hosmer-Lemeshow $P$-value $=0.076$; Nagelkerke $R^{2}=0.298$. Factors removed from the model because of non-significant association were: age, religion, region of residence, type of university, health specialty, believing that alcohol is dangerous for health and for pregnant women, age at first consumption, place of first consumption, believing that it is acceptable to get drunk from time to time and believing that it is dangerous to drink and drive. ORa $=$ adjusted odds ratio; $C I=$ confidence interval.

patterns. In Western societies as many females as males consumed alcohol [1], whereas in Lebanon more males than females were found to be at risk. The explanation for this discrepancy could be the fact in our more conservative society [10] fewer females than males are used to drinking on a regular basis. This difference between men and women was demonstrated in a recent worldwide cross-national comparison [17]. However, Karam et al. found that alcohol consumption among women was increasing and that once they became an ever-alcohol consumer, religion did not affect alcohol dependence [16]. Belief in God and religious practice per se seemed a protective factor against alcohol use disorders in Lebanese students [18].

Higher age (20-22 years) was accompanied by a higher rate of harmful alcohol drinking than the lower age category (17-19 years). This is probably due to greater independence from society's rules in advanced college years than when freshly graduated from high school. It could also reflect the time period to acquire the habit of drinking alcohol during the years of university education. As for the type of university, the annual costs of private universities are many-fold higher than the public Lebanese University. The majority of private university students belong to a higher socioeconomic status, which is reflected in a way of living full of social gatherings between relatives and friends with many occasions for drinking alcohol. Thus, the rate of harmful alcohol consumption was higher in private universities. Concerning the region of residence, students living in Beirut and Mount Lebanon were more likely to have an AUDIT score $\geq 8$ and this is probably due to their higher socioeconomic status as well as the greater number of restaurants, pubs and clubs offering alcohol in those regions. However, all of these factors (age, region, age and religious beliefs) could not on their own explain the difference between students' harmful drinking; they were actually confounded by other factors of knowledge and peers' influence in the multivariate analysis.

An interesting finding was that personal beliefs about alcohol drinking had a significant but limited effect on the risk of harmful drinking; all beliefs that showed a significant effect on bivariate analysis seemed to be confounded by peers' opinion about alcohol, peers' drinking habits and knowledge about alcohol effects. Although both knowledge about alcohol effects and the influence of peers are important, the former seemed to have a limited effect on harmful drinking in our study. As students of health specialties would be expected to be aware of the dangers of alcohol, it is not surprising that the results showed that they were less prone to harmful alcohol drinking. This result was also apparent in the multivariate analysis. In fact, the regression analysis of factors associated with harmful drinking eliminated many factors within the personal beliefs category from the model, which means that personal beliefs had a limited effect on the risk of harmful drinking. Nevertheless, believing that frequent and massive consumption of alcohol was dangerous remained a significant risk factor with an adjusted OR of 2.94 .

As for peers' opinion and behaviours, they seem to be the major driving force for harmful drinking of youth; many factors showed significant associations with harmful alcohol drinking, such as believing that their friends agreed with drinking, higher frequency of alcohol consumption with friends and higher number of friends who drink on a regular basis. Those factors had the highest explanatory ratio of the dependent variable variance; they contributed to a higher alcohol level among consumers, thus leading to possible dangerous social and health outcomes. This concept has been demonstrated by others, such as Song et al. [19], Trucco et al. [20], and van der Zwaluw et al. [21]. Our study highlights the need for the introduction of peer education about alcohol consumption and its dangers in all Lebanese universities; a similar activity was initiated among Lebanese/ Armenian people to prevent substance abuse [22]. We suggest it could be generalized to other young Lebanese as well.

We are aware of the limitations of this study: a selection bias is possible since the sample was not randomly chosen and an information bias is possible, particularly given the delicate nature of the subject. Moreover, to keep the questionnaire simple we did not define 
the terms "frequent" and "massive" consumption in the questions, as our objective was simply to gain an idea about personal beliefs rather than make a formal evaluation. Thus, our results could be overestimating or underestimating the prevalence of alcohol consumption or harmful drinking and its associated factors; however, these biases would be non-differential and the associations found would only be directed towards the null. Additional studies would be necessary to further refine these results in the Lebanese youth population.

In conclusion, harmful alcohol drinking was common among university students in Lebanon and was mainly affected by peers' opinions and behaviours. Interventions are needed to help reduce this significant rate of regular alcohol consuming among students in our country and the danger of massive consumption, especially during gatherings of friends.

\section{References}

1. Tse EC. A comparative analysis of alcohol consumption pattern among global university students. Paper presented at the 2011 Annual Conference of the International Council on Hotel, Restaurant, and Institutional Education. Denver, Colorado, 27-30 July 2011 (http://scholarworks.umass.edu/refereed/ ICHRIE_2011/Saturday/10, accessed 28 January 2013).

2. Karam E, Kypri K, Salamoun M. Alcohol use among college students: an international perspective. Current Opinion in Psychiatry, 2007, 20:213-221.

3. Wechsler $\mathrm{H}$ et al. College alcohol use: a full or empty glass? Journal of American College Health, 1999, 47:247-252.

4. Hingson R et al. Magnitude of alcohol-related mortality and morbidity among U.S. college students ages 18-24: changes from 1998 to 2001. Annual Review of Public Health, 2005, 26:259-279.

5. Singleton RA Jr, Wolfson AR. Alcohol consumption, sleep, and academic performance among college students. Journal of Studies on Alcohol and Drugs, 2009, 70:355-363.

6. Courtois $R$ et al. Liens entre stresseurs, sante psychique et premieres consommations de tabac et d'alcool a la preadolescence. [Links between stress factors, mental health and initial consumption of tobacco and alcohol during preadolescence]. L'Encéphale, 2007, 33:300-309.

7. Gossop M, Marsden J, Stewart D. Dual dependence: assessment of dependence upon alcohol and illicit drugs, and the relationship of alcohol dependence among drug misusers to patterns of drinking, illicit drug use and health problems. Addiction, 2002, 97:169-178.

8. Chafetz ME. Consumption of Alcohol in the Far and Middle East. New England Journal of Medicine, 1964, 271:297-301.

9. Karam E et al. Use and abuse of licit and illicit substances: prevalence and risk factors among students in Lebanon. European Addiction Research, 2000, 6:189-197.

10. Tohmé-Tabet A. Women, intangible heritage and development in Arab States. Paris, United Nations Educational, Scientific and Cultural Organization, 2001. (http://www.unesco.org/culture/ich/doc/src/00161-EN.pdf, accessed 28 January 2013).

11. Karam EG et al. A rapid situation assessment (RSA) study of alcohol and drug use in Lebanon. Le Journal Medical Libanais, 2010, 58:76-85.
12. Babor TF et al. AUDIT. The alcohol use disorders identification test: guidelines for use in primary health care. Geneva, World Health Organization, 1992.

13. Babor TF, Higgins-Biddle JC. Brief intervention for hazardous and harmful drinking: a manual for use in primary care. Geneva, World Health Organization, 2001.

14. Chen $\mathrm{CH}$, Chen WJ, Cheng ATA. New approach to the validity of the alcohol use disorders identification test: stratumspecific likelihood ratios analysis. Alcoholism, Clinical and Experimental Research, 2005, 29:602-608.

15. Selin KH. Test-retest reliability of the alcohol use disorder identification test in a general population sample. Alcoholism, Clinical and Experimental Research, 2003, 27:1428-1435.

16. Karam EG et al. Alcohol use among university students in Lebanon: prevalence, trends and covariates. The IDRAC University Substance Use Monitoring Study (1991 and 1999). Drug and Alcohol Dependence, 2004, 76:273-286.

17. Wells JE et al. Cross-national comparisons of sex differences in opportunities to use alcohol or drugs, and the transitions to use. Substance Use \& Misuse, 2011, 46:1169-1178.

18. Ghandour LA, Karam EG, Maalouf WE. Lifetime alcohol use, abuse and dependence among university students in Lebanon: exploring the role of religiosity in different religious faiths. Addiction (Abingdon, England), 2009, 104:940-948.

19. Song EY et al. Everyone says it's ok: adolescents' perceptions of peer, parent, and community alcohol norms, alcohol consumption, and alcohol-related consequences. Substance Use and Misuse, 2012, 47:86-98.

20. Trucco EM, Colder CR, Wieczorek WF. Vulnerability to peer influence: a moderated mediation study of early adolescent alcohol use initiation. Addictive Behaviors, 2011, 36:729-736.

21. Van der Zwaluw CS, Larsen H, Engels RC. Best friends and alcohol use in adolescence: the role of the dopamine D4 receptor gene. Addiction Biology, 2011, 17(6):1036-1045.

22. Arevian M. Training trainees, young activists, to conduct awareness campaigns about prevention of substance abuse among Lebanese/Armenian young people. Journal of Interprofessional Care, 2010, 24:173-182. 